\title{
Hydrocortisone-enhanced growth of Aspergillus spp.: implications for pathogenesis
}

\author{
Tony T. C. Ng, ${ }^{1,3}+$ Geoffrey D. Robson ${ }^{2}$ and David W. Denning ${ }^{1,3}$
}

Author for correspondence: David W. Denning. Tel: +4461787 4362. Fax: +44617877432.

1 Department of Microbiology, Hope Hospital, Salford, UK

2 Microbiology Group, School of Biological Sciences, University of Manchester, Oxford Road, Manchester M13 9PL, UK

3 Section of Infectious Diseases, University Department of Medicine, Hope Hospital, Eccles Old Road, Salford M6 8HD, UK

\begin{abstract}
Aspergillus fumigatus and Aspergillus flavus are the most common cause of invasive mould infections worldwide and carry a high mortality. Corticosteroid therapy and Cushing's disease are associated with an increase in invasive aspergillosis. Corticosteroids impair immune function in mammals and, specifically, the conidicidal activity of human macrophages, which was thought to be sufficient explanation for this increased risk. However, we have found a $\mathbf{3 0 - 4 0 \%}$ increase in growth rate of $A$. fumigatus and $A$. flavus exposed to pharmacological doses of hydrocortisone (a human glucocorticoid), suggesting an alternative or additional mechanism for the association. No significant effect was observed with other human steroids such as testosterone, oestradiol or progesterone, though a smaller $(21 \%)$ but significant growth rate increase was obtained with the fungal sterol ergosterol. The presence of a ligand/receptor system is therefore possible in pathogenic Aspergillus spp. Although corticosterone-binding proteins have been identified in some yeast species, a demonstrable physiological effect has been lacking. Interruption of the putative ligand/receptor interaction could have a major effect on the growth and pathogenicity of A. fumigatus, providing opportunities for the development of alternative therapeutic strategies to those currently available.
\end{abstract}

Keywords: Aspergillus spp., hydrocortisone, aspergillosis, ergosterol, growth

\section{INTRODUCTION}

Aspergillus spp. are remarkable pathogens, affecting a wide range of hosts including plants, insects, birds and marine and land-based mammals, including man. Increasing numbers of immunocompromised patients and an increased success in treating bacterial infections have led to the emergence of invasive aspergillosis (most commonly caused by Aspergillus fumigatus) as one of the most comrinon life-threatening opportunistic infections. The proportional incidence of disseminated aspergillosis at autopsy has risen from $17 \%$ in $1978-1982$ to $60 \%$ in 1987-1992 of all systemic mycoses (Groll et al., 1993). Characteristically, neutropenic and bone marrow transplant patients, solid organ transplant recipients (Denning \& Stevens, 1990) (especially liver transplant patients) and patients with AIDS (Denning et al., 1991) or chronic granulomatous disease are afflicted. Mortality rates vary from $30-95 \%$.

† Present address: Department of Immunology, St. Bartholomew's Hospital, 38 Little Britain, West Smithfield, London EC1A 7BE.
In particular, endogenous hypercortisolaemia or pharmacological doses of corticosteroid have been identified as a risk factor for disseminated aspergillosis (Graham \& Tucker, 1984; Palmer et al., 1991). This predisposition to fungal infection was thought to be primarily due to the inhibitory effect of corticosteroid on the monocytemediated damage to fungal hyphae (Diamond, 1983) and the conidicidal activity of tissue macrophages (Schaffner, 1985). A direct effect of human cortisol on the growth or metabolism of $A$. fumigatus has so far not been demonstrated.

This study was conducted to explore the possibility of a direct interaction between human cortisol and $A$. fumigatus by measuring the effect of pharmacological doses of hydrocortisone on the in vitro growth of two clinical isolates of $A$. fumigatus.

\section{METHODS}

Isolates. Five isolates of Aspergillus were studied. Two were clinical isolates of A. fumigatus, AF-6 and AF-10. The former was the cause of fatal disseminated invasive aspergillosis in a renal transplant recipient; autopsy showed disseminated disease 
in the brain, lung and heart valve. AF-10 was the cause of invasive pulmonary aspergillosis in a woman with multiple sclerosis treated with adrenocorticotrophic hormone (ACTH), which raises endogenous cortisol concentrations. She responded to withdrawal of ACTH and amphotericin B therapy. AF-10 is accessioned as ATTC 90240. One isolate each of $A$. flavus, 4 . oryzae and $A$. niger were also tested. The $A$. flavus isolate was a laboratory contaminant (AFL14/92). A. oryzae (IFO 1477) and A. niger (AB4.1; from Dr D. Archer, AFRC, Norwich) were standard laboratory isolates.

Growth measurement. We measured the effect of hydrocortisone sodium succinate (Solucortef; Upjohn) on the growth of Aspergillus. First, we measured the specific growth rate of fungal mycelia as described previously by Robson et al. (1991). Briefly, inocula were made up by diluting the spore suspension (final spore concentration, $10^{2}$ c.f.u. $\mathrm{ml}^{-1}$ ) in $10^{-6} \mathrm{M}$ hydrocortisone solution or PBS $(0.145 \mathrm{M} \mathrm{NaCl}, 0.15 \mathrm{M}$ sodium phosphate; control) and then spreading onto agar-solidified Vogel's medium (containing $5 \mathrm{mM}$ glucose) prepared with or without hydrocortisone (overlaid with sterile Cellophane to ensure that the mycelia grew in a single plane). Plates were incubated at $32^{\circ} \mathrm{C}$ or $37^{\circ} \mathrm{C}$ in a thermostatically controlled electrically heated box. Growth in exponential-phase was monitored by measuring the total hyphal length of germlings (each arising from a viable spore) at hourly intervals over a $5 \mathrm{~h}$ period using a Measure Mouse graphics system (Analytical Measuring Systems, Cambridge) and an Amstrad PC 1520 connected to a Nikon microscope. A Panasonic WV-CD20 video camera relayed the microscope image to a computer monitor on which it could be traced using a computer mouse. At each time-point, five replicate germlings per plate were measured. Specific growth rate was calculated from the slope of the natural logarithm of total hyphal length versus time as described by Trinci (1974). The difference between the mean specific growth rates in the presence and absence of hydrocortisone was analysed using analysis of covariance (ANCOVA).

The second method measures growth indirectly by the rate of incorporation of $\mathrm{N}$-acetyl-D- $\left[1-{ }^{14} \mathrm{C}\right]$ glucosamine (Amersham International). Chitin, which makes up $20 \%$ of the fungal cell wall, is largely composed of polymers of acetylglucosamine. The inoculum $\left(10^{7}\right.$ c.f.u. $\left.\mathrm{ml}^{-1} ; 0 \cdot 1 \mathrm{ml}\right)$ was diluted in $2 \mathrm{ml}$ Vogel's medium in the presence or absence of various concentrations of hydrocortisone and incubated at $37^{\circ} \mathrm{C}$ on a rotary shaker after the addition of $0.1 \mu \mathrm{Ci}(3.7 \mathrm{kBq})$ of the labelled substrate. In exponential phase, at hourly intervals, four tubes, each containing a different concentration of hydrocortisone $\left(10^{-8}, 10^{-7}, 10^{-6}, 10^{-5} \mathrm{M}\right)$, were retrieved from the incubator along with the control. Trichloroacetic acid $(2 \mathrm{ml})$ was added to each to remove any free substrate that was not incorporated in the cell wall. Tubes were centrifuged at 2000 r.p.m. for $5 \mathrm{~min}$ and supernatants discarded. Pellets were each washed three times with PBS, mixed with $2.2 \mathrm{ml} 1 \mathrm{M}$ sodium hydroxide and then sonicated for 1-2 min. The homogeneous solution obtained $(2 \mathrm{ml})$ was placed into $2 \mathrm{ml}$ Ultima Gold (Packard Instrument) in a scintillant vial and radioactive emission measured for $10 \mathrm{~min}$ in a 1211 Minibeta liquid scintillation counter. Counts per minute (c.p.m.) were converted into disintegrations per minute (d.p.m.) using the quench correction curve previously derived. The rate of cell-wall uptake of radioactive substrate was derived from the slope of the natural logarithm of sample radioactivity versus time. The difference in slopes (Gardner \& Altman, 1989) was analysed using Fig-P (Biosoft).

The effects of ergosterol (a fungal sterol) and three other human steroids, namely $17 \beta$-oestradiol $\left(\mathrm{E}_{2} ;\right.$ Sigma $)$, progesteror.e
(Sigma) and testosterone (Sigma) on A. fumigatus (AF-10) were also investigated using a simple screening test adapted from the radiometric assay. For each sterol (at $10^{-6} \mathrm{M}$ concentration), a set of four replicate tubes were prepared as described and grown at $37^{\circ} \mathrm{C}$ along with four replicate controls (live conidia without added steroid). These were retrieved at mid-exponential phase, processed and the total amount of assimilated radioactivity $\left(\mathrm{r}^{\text {total }}\right)$ measured. Growth increase (\%) was defined by the equation:

[(mean $r^{\text {total }}$ of the four replicates $) /$ (mean $\mathrm{r}^{\text {total }}$ of the four controls) -1$] \times 100 \%$

\section{RESULTS AND DISCUSSION}

Mean specific growth rate (at $37^{\circ} \mathrm{C}$ ) was found to increase, in the presence of $10^{-6} \mathrm{M}$ hydrocortisone, by $40 \%$ (from $0.62 \mathrm{~h}^{-1}$ to $0.87 \mathrm{~h}^{-1} ; P=0.0001$ by ANCOVA) (Fig. 1). The effect of hydrocortisone is independent of temperature as similar increases in growth were obtained in two subsequent experiments repeated at $32{ }^{\circ} \mathrm{C}[36 \%$; from $0.478 \mathrm{~h}^{-1}$ to $0.652 \mathrm{~h}^{-1}(P=0.0008)$ and $43 \%$; from $0.426 \mathrm{~h}^{-1}$ to $\left.0.607 \mathrm{~h}^{-1}(P=0.0002)\right]$. Similarly, the rate of cell-wall uptake of labelled acetylglucosamine was found to increase by $140 \%$ with $10^{-6} \mathrm{M}$ hydrocortisone [difference in slopes $=0.111(0.193-0.082) \mathrm{h}^{-1}, 95 \%$ $\mathrm{CI}=0.008-0 \cdot 214 \mathrm{~h}^{-1}$ ] (Fig. 2a). In the repeat experiment, a $70 \%$ increase [difference in slopes $=0.081(0.197-$ $\left.0 \cdot 116) \mathrm{h}^{-1}, 95 \% \mathrm{CI}=0 \cdot 012-0 \cdot 15 \mathrm{~h}^{-1}\right]$ was observed. This effect was shown to be dose-dependent (Fig. 2b), with $10^{-6} \mathrm{M}$ being the concentration that corresponded to the maximum growth increase. Pharmacokinetically, this concentration is roughly equivalent to the peak serum level achieved in humans following an intravenous administration of $20 \mathrm{mg}$ hydrocortisone (Derendorf et al., 1991). No effect on time to germination was observed (data not shown).

Similar experiments with other species of Aspergillus showed that the effect of hydrocortisone is probably species-specific in that it had no effect on the growth rate of $A$. oryzae or $A$. niger whereas the specific growth rate of a laboratory strain of $A$. flavus was increased by $30 \%$ from $0.45 \mathrm{~h}^{-1}$ to $0.593 \mathrm{~h}^{-1}$ (Fig. 3). This difference was not statistically significant, $P=0.3$ by ANCOVA, but un-

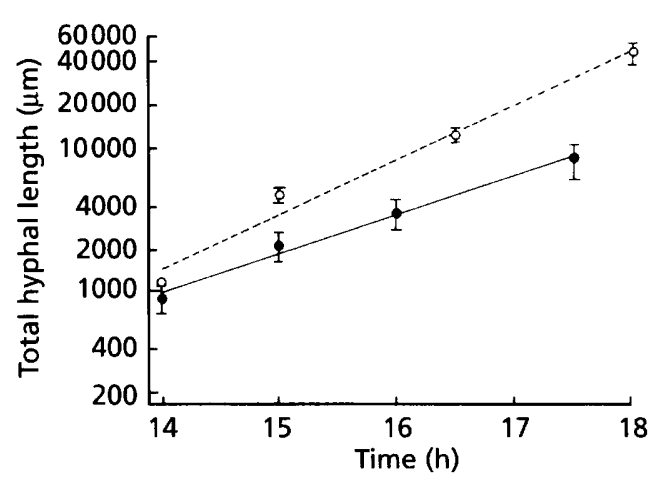

Fig. 1. Increase in total hyphal length $(\mu \mathrm{m})$ with time $(\mathrm{h})$ in germlings of isolate AF- 6 grown at $37^{\circ} \mathrm{C}$ with (O) or without (e) $10^{-6} \mathrm{M}$ hydrocortisone. At each time point the mean \pm SEM of five replicate germlings was plotted. 

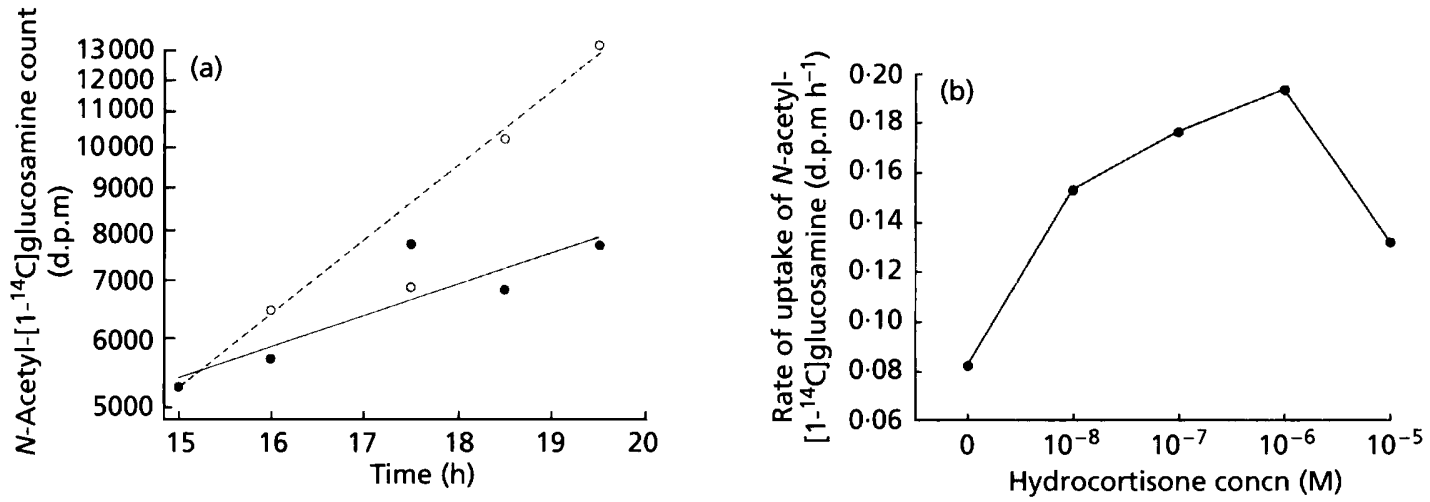

Fig. 2. Effect of the addition of hydrocortisone on the rate of incorporation of radiolabelled $N$-acetylglucosamine into the cell wall in isolate AF-10. (a) $10^{-6} \mathrm{M}$ hydrocortisone (O) versus no steroid control (O). (b) Dose responsive increase in growth rate with hydrocortisone $\left(10^{-8}-10^{-5} \mathrm{M}\right)$.

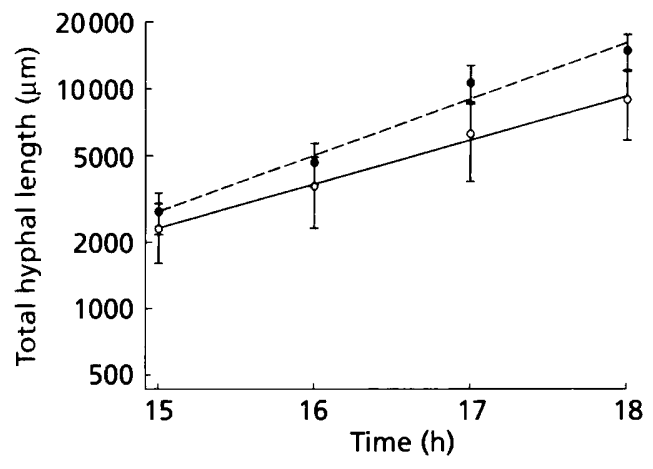

Fig. 3. Increase in total hyphal length $(\mu \mathrm{m})$ with time $(h)$ in germlings of a laboratory strain of $A$. flavus grown at $32{ }^{\circ} \mathrm{C}$ with $(0)$ or without $(O) 10^{-6} \mathrm{M}$ hydrocortisone. At each time point the mean \pm SEM of three or four replicates was plotted.

Table 1. Effects of different sterols on the growth of AF10 as measured by a simplified radiometric assay

\begin{tabular}{|lcc|}
\hline $\begin{array}{l}\text { Sterol } \\
\left(\mathbf{1 0}^{-\mathbf{6}} \mathbf{M}\right)\end{array}$ & $\begin{array}{c}\text { Growth } \\
\text { increase } \\
\text { relative to } \\
\text { control* }\end{array}$ & $\begin{array}{c}\boldsymbol{P} \\
\text { value }\end{array}$ \\
\hline Hydrocortisone & $44 \%$ & $0 \cdot 03$ \\
Ergosterol & $30 \%$ & $0 \cdot 183$ \\
17 $\beta$-oestradiol & $8 \%$ & $0 \cdot 277$ \\
Progesterone & $3 \%$ & $0 \cdot 937$ \\
Testosterone & $15 \%$ & $0 \cdot 211$ \\
\hline
\end{tabular}

* Mean $\mathrm{r}^{\text {total }}$ (c.p.m.) of controls $=15927$ and 9209, respectively, in two experiments.

$\dagger$ Actual concentration $2.5 \times 10^{-6} \mathrm{M}$.

fortunately it was only possible to do one experiment with three or four replicates per time point.

Table 1 compares the effects of different sterols on the growth of $A$. fumigatus (AF-10) detected by the simplified

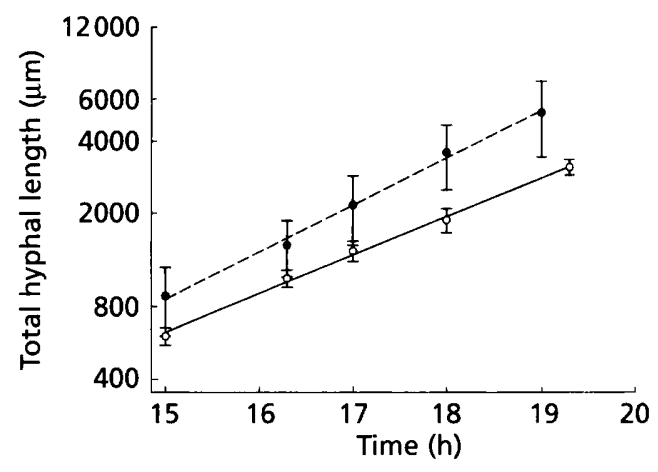

Fig. 4. Effect of the addition of $1 \mu \mathrm{g}$ ergosterol $\mathrm{ml}^{-1}(0)$ on the specific growth rate of AF-10 grown at $30^{\circ} \mathrm{C}$. O, No steroid control.

radiometric assay. The figures presented represent the mean of two experiments. Among the five sterols tested, only hydrocortisone produced a significant growth increase $(44 \%)$. The results were analysed by two-way analysis of variance (ANOVA), which showed that the effect of hydrocortisone was the same in each experiment $\left(F_{1,8}=0 \cdot 1, P=0 \cdot 76\right)$ and there was a significant increase in growth with hydrocortisone in comparison to the control $\left(F_{19}=6.5, P=0.03\right)$. The percentage growth increase $(30 \%, P=0.183)$ induced by the addition of $10^{-6} \mathrm{M}\left(1000 \mathrm{ng} \mathrm{ml}^{-1}\right)$ ergosterol was second to that of hydrocortisone. These results were similar to those obtained using the computer Measure Mouse system, which showed a $21 \%$ increase (from 0.369 to $0.448 \mathrm{~h}^{-1}$; $P=0.0001$ by ANCOVA) in specific growth rate with the addition of $10^{-6} \mathrm{M}$ ergosterol (Fig. 4). Small growthrate increases were seen at ergosterol concentrations of $2.5 \times 10^{-7} \mathrm{M}\left(0.422 \mathrm{~h}^{-1} ; \quad P \geqslant 0.05\right)$ and $2.5 \times 10^{-5} \mathrm{M}$ $\left(0 \cdot 434 \mathrm{~h}^{-1} ; P>0 \cdot 05\right)$.

In this study we have unequivocally demonstrated, for the first time, a direct interaction between human cortisol and A. fumigatus resulting in a significant increase in growth. Several other interactions between human hormones and 
fungi have been documented, some of which have proved to be important in the pathogenesis of certain fungal diseases. For instance, progesterone and $17 \beta$-oestradiol $\left(E_{2}\right)$ both promote the growth and endospore release of Coccidioides immitis (Powell et al., 1983), therefore accounting for the increased incidence of coccidioidomycosis in pregnancy. Infections with Paracoccidioides brasiliensis, on the other hand, occur predominantly in males (among those who acquire the disease after puberty), possibly as a result of the inhibitory effect $17 \beta$ oestradiol has on its mycelium- to yeast-form transformation (Restrepo et al., 1984), an essential preliminary step in the establishment of infection. In addition, specific binding proteins for human hormones have been found in various fungi, e.g. corticosterone-binding protein $(\mathrm{CBP})$ in Candida albicans and six other Candida spp. (Loose et al., 1983a); specific binders for $\mathrm{E}_{2}$ in Paracoccidioides brasiliensis (Loose et al., 1983b), C. albicans, Candida glabrata (Powell et al., 1984) and Saccharomyces cerevisiae (Feldman et al., 1982); luteinizing hormone/human chorionic gonadotropin binding sites in C. albicans and Candida tropicalis (Bramley et al., 1990). Some of these binding proteins, upon hormonal binding, appear to mediate the morphological changes characteristic of the pathological process seen in the corresponding fungal disease, while others, such as the CBP in C. albicans, have no demonstrable effect upon fungal growth, phase conversion or glucose oxidation (Loose et al., 1983a). Unlike yeast:;, we found no significant effect of $E_{2}$, progesterone or testosterone on the growth of AF-10. The effect of cortisol on Aspergillus may therefore be unique in that it is not mimicked by other human steroids. Interestingly, ergosterol also increases the growth of AF-10 in a dosedependent manner. Maximum increase in specific growti rate was obtained at $1 \mu \mathrm{g} \mathrm{ml}^{-1}\left(2.5 \times 10^{-6} \mathrm{M}\right)$, the same concentration that was associated with an increase in protein kinase activity in S. cerevisiae (Dahl et al., 1987), The intracellular signalling pathways of ergosterol (at least in Saccharomyces) and some of the mammalian hormones/cytokines are similar in that both result in an increase in phosphoinositide hydrolysis [i.e. conversion of phosphatidylinositol bisphosphate $\left(\mathrm{PIP}_{2}\right)$ to inositol triphosphate $\left(\mathrm{IP}_{3}\right)$ and diacylglycerol], which in turn leads to protein kinase activation and cell proliferation (Dahl \&: Dahl, 1985). The mechanism(s) by which hydrocortisone affects fungal growth is, however, unknown, but may involve binding to a glucocorticoid receptor similar to that found in Candida and mammals. The mammalian glucocorticoid receptor includes, for maintaining its highaffinity steroid binding conformation, the highly conserved heat-shock-protein 90 complex (hsp90) (Meschinchi et al., 1990). There is considerable immunological cross-reactivity between the hsp90 antigens of $C$. albicans and mammals and some of the immunodominant antigens of A. fumigatus, including the $88 \mathrm{kDa}$ antigen (Riehl et al., 1985; Burnie \& Matthews, 1991). These data lend credence to the suggestion that $A$. fumigatus possesses a glucocorticosteroid receptor which may be linked to hsp90.

Our discovery that corticosteroid promotes the growth of
A. fumigatus may have important implications for the pathogenesis of aspergillosis, as the specific growth rate of $0.9 \mathrm{~h}^{-1}$ of $A$. fumigatus grown in the presence of hydrocortisone at $37^{\circ} \mathrm{C}$ (corresponding to a doubling time of $48 \mathrm{~min}$ ) makes it one of the fastest growing fungi described. Currently we are working to identify and characterize the putative corticosteroid-binding receptor in A. fumigatus, which may enable us to develop alternative therapeutic agents to those currently available.

\section{ACKNOWLEDGEMENTS}

We are indebted to technical assistance from Linda Hall and statistical advice from Sally Hollis. Supported by grants from SERC and The Fungal Research Trust.

\section{REFERENCES}

Bramley, T. A., Menzies, G. S., Williams, R. J., Adams, D. J. \& Kinsman, O. S. (1990). Specific, high-affinity binding sites for human luteinizing hormone $(\mathrm{hL} \cdot \mathrm{H})$ and human chorionic gonadotrophin (hCG) in Candida species. Biocbem Biophys Res Commun 167, 1050-1056.

Burnie, J. P. \& Matthews, R. C. (1991). Heat shock protein 88 and Aspergillus infection. J Clin Microbiol 29, 2099-2106.

Dahl, C., Biemann, H. P. \& Dahl, J. (1987). A protein kinase antigenically related to $\mathrm{pp} 60 \mathrm{v}$-src possibly involved in yeast cell cycle control: positive in vivo regulation by sterol. Proc Natl Acad Sci US A 84, 4012 -4016.

Dahl, J. S. \& Dahl, C. E. (1985). Stimulation of cell proliferation and polyphosphoinositide metabolism in Saccharomyces cerevisiae GL7 by ergosterol. Biochem Biophys Res Commun 133, 844-850.

Denning, D. W. \& Stevens, D. A. (1990). Antifungal and surgical treatment of invasive aspergillosis: review of 2121 published cases. Rev Infect Dis 12, 1147-1201.

Denning, D. W., Follansbee, S., Scolaro, M., Norris, S., Edelstein, D. \& Stevens, D. A. (1991). Pulmonary aspergillosis in AIDS. $N$ Engl J Med 324, 654-662.

Derendorf, H., Mollmann, H., Barth, J., Mollmann, C., Tunn, S. \& Krieg, M. (1991). Pharmacokinetics and oral bioavailability of hydrocortisone. J Clin Pharmacol 31, 473-476.

Diamond, R. D. (1983). Inhibition of monocyte-mediated damage to fungal hyphae by steroid hormones. J Infect Dis 147, 160.

Feldman, D., Do, Y., Burshell, A., Stathis, P. \& Loose, D. S. (1982). An estrogen-binding protein and endogenous ligand in Saccharomyces cerevisiae: possible hormone receptor system. Science 218, 297-298.

Gardner, M. J. \& Altman, D. G. (1989). Statistics with Confidence Confidence Intervals and Statistical Guidelines. London: BMJ.

Graham, B. S. \& Tucker, W. S. (1984). Opportunistic infections in endogenous Cushing's syndrome. Ann Intern Med 101, 334- 338.

Groll, A., Shah, P. M., Menzel, C., Just, G., Schneider, M. \& Hubner, K. (1993). Invasive mycosis in post-mortem findings. Trends in Invasive Fungal Infections II (Manchester, UK). Abstract no. 1.

Loose, D. S., Stevens, D. A., Schurman, D. J. \& Feldman, D. (1983a). Distribution of a corticosteroid-binding protein in Candida and other fungal genera. J Gen Microbiol 129, 2379-2385.

Loose, D. S., Stover, E. P., Restrepo, A., Stevens, D. A. \& Feldman, D. (1983b). Estradiol binds to a receptor-like cytosol binding protein and initiates a biological response in Paracoccidioides brasiliensis. Proc Natl Acad Sci USA 80, 7659--7663. 
Meshinchi, S., Sanchez, E. R., Martell, K. J. \& Pratt, W. B. (1990). Elimination and reconstitution of the requirement for hormone in promoting temperature-dependent transformation of cytosolic glucocorticoid receptors to the DNA-binding state. $J$ Biol Chem 265, 4863 4870.

Palmer, L. B., Greenberg, H. E. \& Schiff, M. J. (1991). Corticosterord treatment as a risk factor for invasive aspergillosis in patients with lung disease. Thorax 46, 15-20.

Powell, B. L., Drutz, D. J., Huppert, M. \& Sun, S. H. (1983). Relationship of progesterone- and estrogen-binding proteins in Coccidioides immitis to coccidioidal dissemination in pregnancy. Infect Immun 40, 478-485.

Powell, B. L., Frey, C. L. \& Drutz, D. J. (1984). Identification of a $17-$ beta-estradiol-binding protein in Candida albicans and Candida (Toruloficis) glabrata. Exp Mycol 8, 304-313.

Restrepo, A., Salazar, M. E., Cano, L. E., Stover, P., Feldman, D. \& Stevens, D. A. (1984). Estrogens inhibit mycelium-to-yeast transformation in the fungus Paracocidioides brasiliensis: implications for resistance of females to paracoccidioidomycosis. Infect Immun 46, 346-353.

Riehl, R. M., Sullivan, W. P., Vroman, B. T., Bauer, V. J., Pearson, G. R. \& Toft, D. O. (1985). Immunological evidence that the nonhormone binding component of avian steroid receptors exists in a wide range of tissues and species. Biochemistry 24, 6586-6591.

Robson, G. D., Wiebe, M. G. \& Trinci, A. P. J. (1991). Exogenous cAMP and cGMP modulate branching in Fusarium graminearum. $J$ Gen Microbiol 137, 963-969.

Schaffner, A. (1985). Therapeutic concent rations of glucocorticoids suppress the antimicrobial activity of human macrophages without impairing their responsiveness to gamma interferon. $J$ Clin Invest 76, 1755-1764.

Trinci, A. P. J. (1974). A study of the kinetics of hyphal extension and branch initiation of fungal mycelia. J Gen Microbio/ 81, 225-236.

Received 8 April 1994; revised 20 May 1994; accepted 20 May 1994. 